\title{
RESÍDUOS PRODUZIDOS PELOS PROCESSADORES DE AÇAÍ NA REGIÃO METROPOLITANA DE BELÉM E AVALIAÇÃO DO SEU POTENCIAL ENERGÉTICO
}

Luana Helena Oliveira Monteiro - eng.luanamonteiro@gmail.com Universidade Federal Rural da Amazônia

Rodrigo Otávio Silva da Costa- eng.rodrigocosta1@gmail.com

Universidade Federal Rural da Amazônia

Paula Fernanda Viegas Pinheiro - engpaulapinheiro@ gmail.com

Universidade Federal Rural da Amazônia 


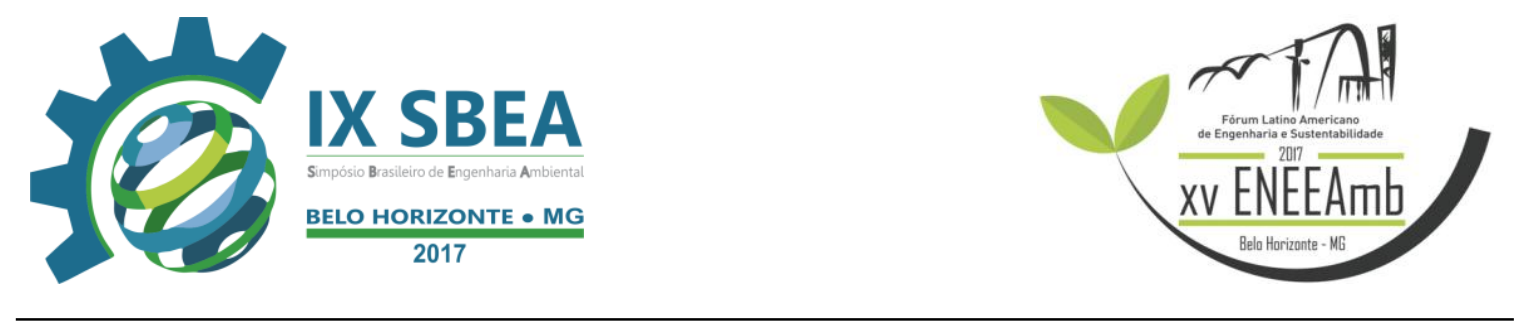

\section{RESUMO}

Considerando que o Pará é o principal produtor de Açaí, sendo responsável por $95 \%$ da produção de açaí do Brasil, o presente artigo, se propõe a estudar a gestão dos resíduos produzidos pelos batedouros de açaí de Belém, por meio da pesquisa quantiqualitativa desta atividade, bem como fornecer subsídios para auxiliar pesquisas futuras correlacionadas a este trabalho. O processo de extração do suco do Açaí, gera como resíduo de forma esférica, popularmente denominado "caroço" este não possui nenhuma aplicação significativa, e por ter grande consumo estes resíduos são depositados em grande quantidade. O caroço do Açaí é um bom combustível de biomassa para ser usado em combustão ou processo de gaseificação. Dos 20 batedores entrevistados no período da safra são gerados 24.288 rasas de açaí, e 17.014 rasas na entre safra. Dos bairros pesquisados, 51 apresentaram potencial para gerar energia elétrica através de biomassa energética, tais dados que podem ser utilizados para pesquisas futuras e que pode de maneira significativa minimiza os impactos ambientais causados pela destinação inadequada dos resíduos do açaí.

Palavras-chave: Açaí, resíduos sólidos, biomassa.

\section{INTRODUÇÃO/OBJETIVO}

A Pesquisa abrange a Região Metropolitana de Belém - RMB, a qual possui cerca de $505 \mathrm{~km}^{2}$ de área, sendo 34,6\% do território formado pela região continental e 65,4\% correspondendo ao conjunto de 39 ilhas (BRASIL, 2016). De acordo com o IBGE (2010) o município apresenta um contingente populacional de 1.393.399 habitantes distribuídos em 71 bairros compondo 08 Distritos Administrativos que funcionam como unidade de planejamento territorial. Sabendo-se da necessidade da análise da gestão de resíduos produzidos pelos batedores de açaí na região, realizou-se o presente estudo.

Nesse contexto, e considerando que a população Belenense possui como hábito alimentar o suco do açaí diariamente, é notável a comercialização de açaí em Belém, o 


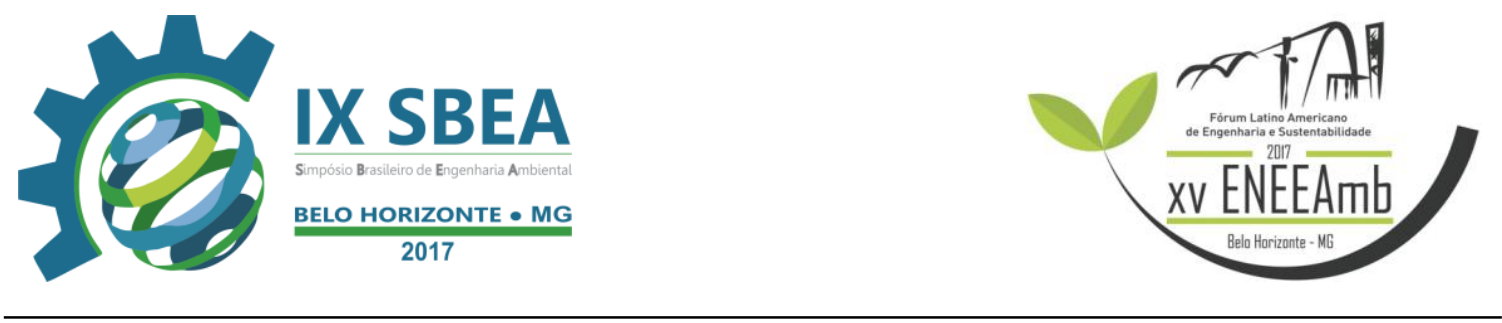

que resulta em uma grande quantidade de caroços, que, muitas vezes, são destinados ao lixão municipal. Isso é um grande problema, não só ambiental, mas também a perda de grande potencialidade que o caroço de açaí possui. Para tanto, analisou-se o gerenciamento dos resíduos produzidos pelos batedores de açaí, despejados nas imediações de ruas, avenidas e córregos, pois não é realizada uma coleta especifica para as resinas provenientes do açaí e também o aproveitamento dos rejeitos para geração de energia.

Não existe um sistema de gestão dos resíduos de açaí bem como foi realizado um estudo do impacto ambiental e das consequências do descarte irregular dos resíduos de açaí ao meio ambiente. Nessa conjuntura, temos como nosso objetivo geral analisar o gerenciamento dos resíduos gerados pelos batedores de açaí na Região Metropolitana de Belém. Mais especificamente, queremos identificar a quantidade de resíduos gerados pelas processadoras de açaí do município de Belém, diagnosticando a quantidade coletada, bem como analisar a destinação dada atualmente aos resíduos do processamento do fruto açaí. Utilizou-se o método hipotético/dedutivo, de natureza quantitativa e qualitativa, tendo por base a revisão bibliográfica.

\section{METODOLOGIA}

O presente estudo foi desenvolvido através de levantamento bibliográfico. Buscaram-se fontes especializadas na temática resíduos sólidos, coleta seletiva e legislações referentes à produção, logística e processamento do fruto açaí, dando destaque à disposição e destinação de seus resíduos. E também foram entrevistados 20 batedores de açaí distribuídos em vários bairros da Região Metropolitana de Belém. Desta maneira, Padilha et al. (2006) utilizaram a estratégia de gestão montada empregou um banco de dados para armazenar os dados coletados sobre as amassadeiras, principalmente: Produção e localização que foram registradas através de coordenadas georeferenciadas. O banco de dados também foi alimentado com informações sobre: Especificações técnicas dos equipamentos empregados e dados de análise laboratorial da biomassa. E também simulações computacionais do funcionamento de uma planta a vapor para 


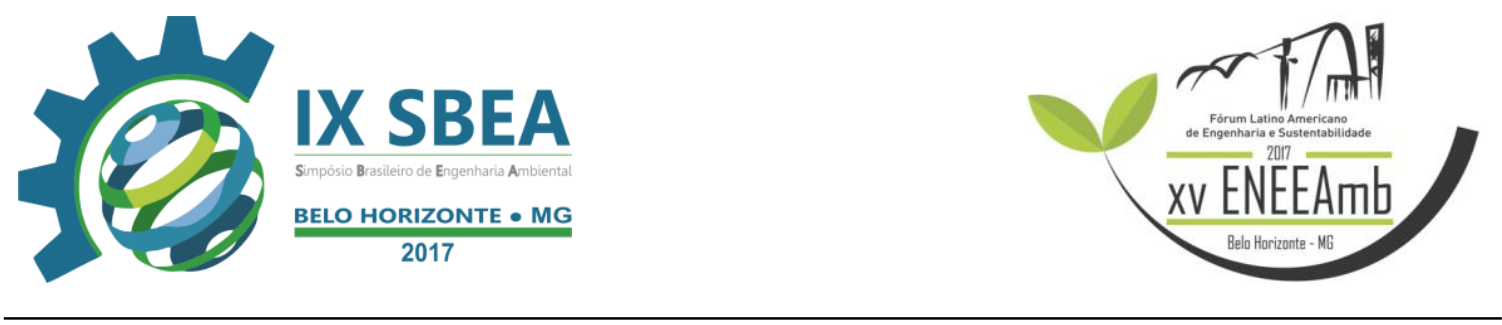

geração de energia com turbinas a vapor, utilizando ciclo Rankine a $21 \mathrm{~kg}$ de vapor/hora - ciclo termodinâmico reversível que converte calor em trabalho.

\section{RESULTADOS E DISCUSSÃO}

De acordo com dados do IBGE, em vinte e dois anos, a produção paraense do fruto apresentou o extraordinário crescimento de 719,28\%, saindo de 113 mil toneladas, em 1990, para 928 mil toneladas, em 2012, equivalente ao crescimento médio de 9,58\%/ano. Devido a este grande aumento na produção de açaí, ao longo destes anos, se tornou-se necessário implantar um melhor controle da quantidade residual produzidos nesta atividade.

Devido a sua importância cultural, o açaí transformou-se, através de lei na bebida e fruta símbolo do estado do Pará e, agora passou a ser priorizado como produto econômico, capaz de gerar renda para a população local e divisas para o país (ANDRADE et al. 2008). Além disso, o açaí lidera o mercado da fruticultura nacional com a exportação chegando a 500 mil toneladas/ano (IBGE, 2010).

Os resíduos sólidos urbanos (RSU) parecem ter como característica peculiar e marcante, uma composição heterogênea, uma vez que os demais (resíduos sólidos industriais e resíduos sólidos especiais) geralmente são gerados a partir de processos controlados, não apresentando grandes variações em suas características. Por esse motivo, serão mais exemplificadas as características dos RSU, embora o conhecimento de tais características também seja extensivo aos demais, para um correto gerenciamento dos mesmos (ANDRADE, 1997).

A Política Nacional de Resíduos Sólidos Brasileira - PNRS (Lei 12.305/10) no seu Art. $3^{\circ}$ define a Disposição Final ambientalmente adequada da seguinte maneira:

Distribuição ordenada de rejeitos em aterros, observando normas operacionais específicas de modo a evitar danos ou riscos à saúde pública e à segurança e a minimizar os impactos ambientais adversos (BRASIL, 2010).

As formas mais conhecidas de disposição final de resíduos são o Aterro Sanitário, Aterro Controlado e Lixão a céu aberto. No Brasil a única forma ainda permitida por Lei é o Aterro Sanitário (MACHADO, 2016). 


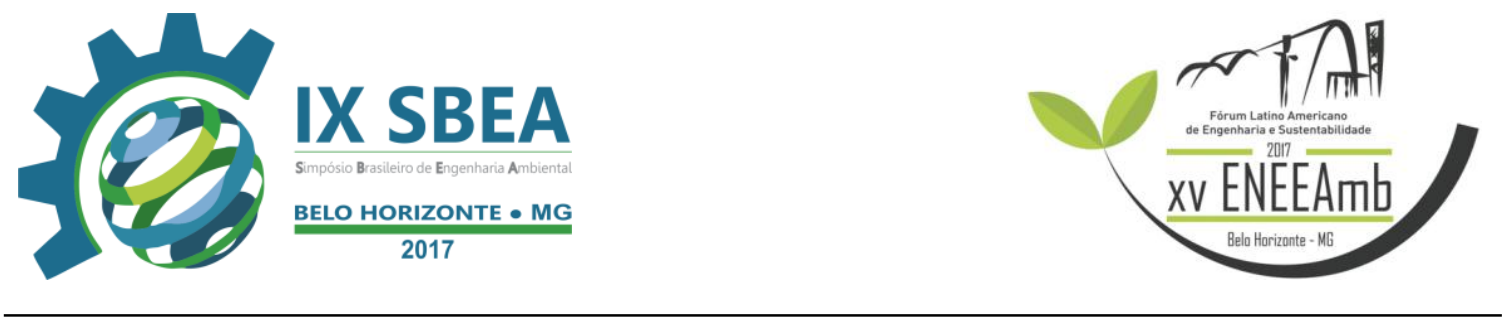

De acordo com Machado (2006) na legislação brasileira a Disposição Final Ambientalmente Adequada de Rejeitos deve ser feita somente para os resíduos que comprovadamente não são mais passíveis de alguma forma de tratamento, seja qual for a forma, ou seja, somente para os rejeitos. Confira o que diz a Lei 12.305/2010:

Desta feita a Lei 12.305/2010 em seu Art. $9^{\circ}$ cita que para a gestão e gerenciamento de resíduos sólidos, deve ser observada a seguinte ordem de prioridade: não geração, redução, reutilização, reciclagem, tratamento dos resíduos sólidos e disposição final ambientalmente adequada dos rejeitos.

A lei prevê ainda que poderão ser utilizadas tecnologias visando à recuperação energética dos resíduos sólidos urbanos, desde que tenha sido comprovada sua viabilidade técnica e ambiental e com a implantação de programa de monitoramento de emissão de gases tóxicos aprovado pelo órgão ambiental.

Fazer a disposição final de rejeitos requer uma completa neutralidade com o meio ambiente. Isso significa que o destino final dos resíduos não deve poluir ou alterar o meio e/ou prejudicar a população local. As principais formas de poluição é a contaminação do solo, dos lençóis freáticos e do ar. As consequências dessa poluição é a proliferação de doenças decorrentes de pragas de ratos, insetos e animais que vivem dos rejeitos assim como doenças ocasionadas pela poluição dos lençóis freáticos como a diarreia (MACHADO, 2016).

Segundo a Embrapa Amazônia Oriental, o período da safra inicia em julho e se estende a dezembro, e a entre safra é de janeiro a junho. Dos 20 batedores de açaí entrevistados, $45 \%$ trabalham há mais de 3 anos no ramo, $35 \%$ há 5 anos e $20 \%$ há mais de dez anos. No gráfico 1 representamos a quantidade de rasas utilizadas por dia no período da safra e no gráfico e 2 o percentual de rasas produzidas na safra conforme cada categoria. Quando se perguntou qual a destinação dos resíduos gerados no batedouro, 90\% responderam que os resíduos são destinados ao aterro sanitário e que o mesmo foi coletado pela prefeitura, os demais $10 \%$ é destinado em vias públicas e geralmente coletados por carroceiros. 
Tabela 1- Quantidade de batedores, total de rasas e porcentagem de resíduos gerados no período da safra.

\begin{tabular}{|l|l|l|l|}
\hline CATEGORIAS & BATEDORES & TOTAL DE RASAS & $\%$ \\
\hline Categoria 1 (3 rasas) & 3 & 9 & 7 \\
\hline Categoria 2 (4 rasas) & 4 & 16 & 12 \\
\hline Categoria 3 (7 rasas) & 11 & 77 & 58 \\
\hline Categoria 4 (15 rasas) & 2 & 30 & 23 \\
\hline TOTAL & 20 & 132 & \\
\hline
\end{tabular}

Fonte: Autor.

Gráfico 1- Quantidade de rasas utilizadas por dia no período da safra do açaí.

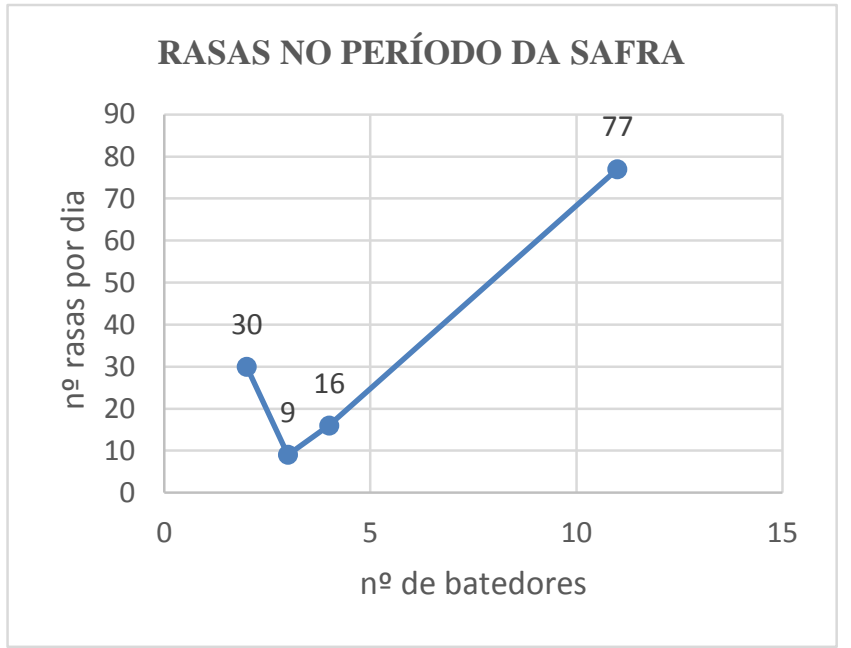

Fonte: Autor.
Gráfico 2-Porcentagem de rasas produzidas na safra do açaí.

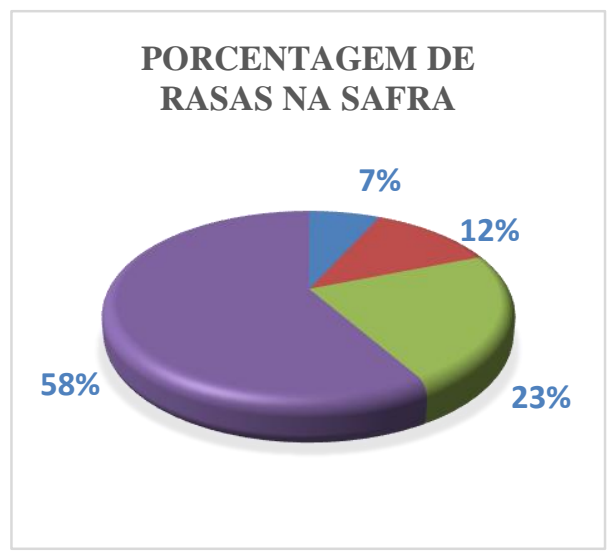

Fonte: Autor.

Já no período da entre safra esses valores diminuem, diariamente a categoria 1A utiliza um total de 10 rasas, categoria 2 utiliza 44 rasas e a categoria $3 \mathrm{~A} 40$ rasas. Como demonstrado na tabela 2 . No gráfico 3 a quantidade de rasas utilizadas por dia no período da entre safra e no gráfico 4 o percentual de rasas na entre safra conforme cada categoria. 
Tabela 2- Quantidade de batedores, total de rasas e porcentagem de resíduos gerados no período da entre safra.

\begin{tabular}{|l|l|l|l|}
\hline CATEGORIAS & BATEDORES & TOTAL DE RASAS & $\%$ \\
\hline Categoria 1A (2 rasas) & 5 & 10 & 11 \\
\hline Categoria 2 (4 rasas) & 11 & 44 & 47 \\
\hline Categoria 3A (10 rasas) & 4 & 40 & 42 \\
\hline TOTAL & 20 & 94 & \\
\hline
\end{tabular}

Fonte: Autor.

Gráfico 3- Quantidade de rasas utilizadas por dia no período da entre safra do açaí.

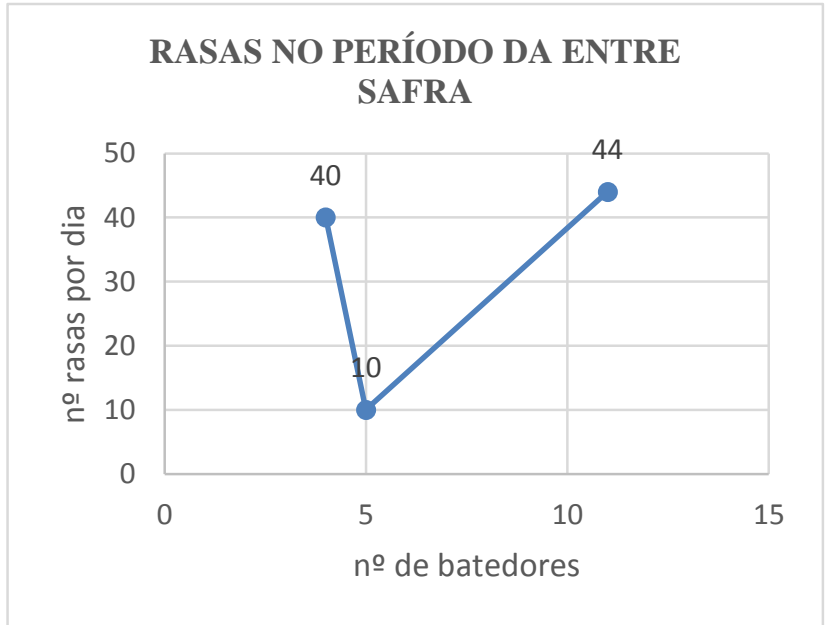

Fonte: Autor.
Gráfico 4-Porcentagem de rasas produzidas na entre safra do açaí.

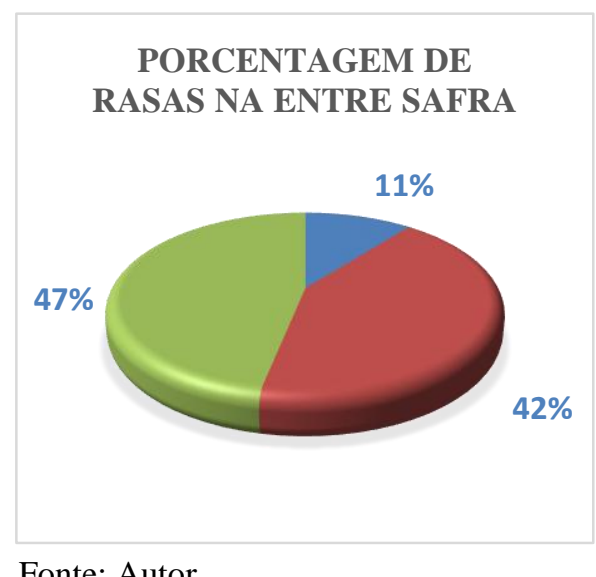

Fonte: Autor.

Segundo Padilha et al (2006), dos 72 bairros pesquisados, 51 apresentaram potencial para gerar energia elétrica através de biomassa energética. O levantamento da quantidade de sacas produzidas por dia e o potencial elétrico de geração são mostrados nos gráficos 5 e 6 . 
Número de sacas de resíduos produzidas por dia pelas "amassadeira" (pontos de venda).

Total de Sacas Produzidas (dia) X Bairro

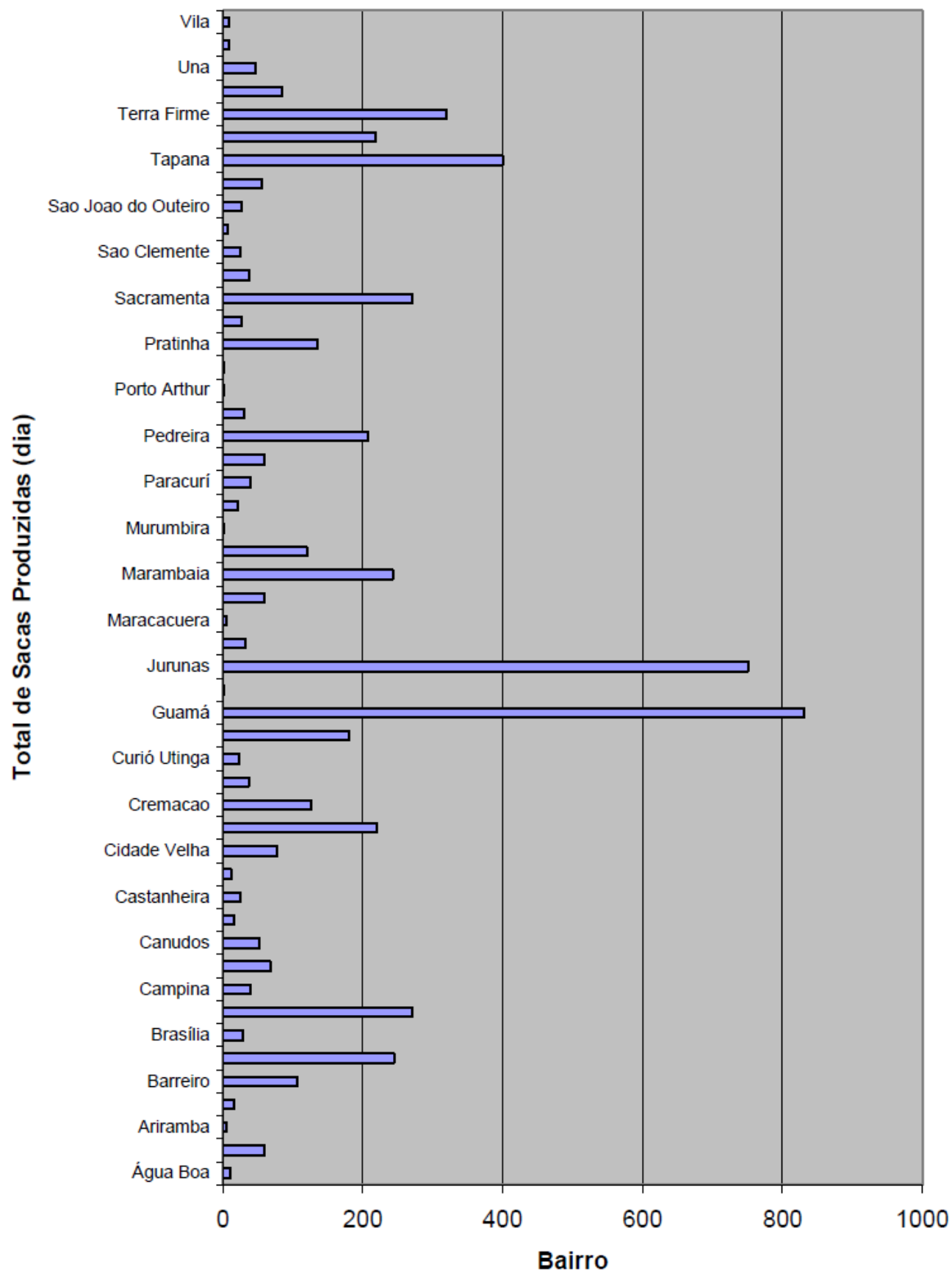

Gráfico 5. Número de sacas por bairro

Fonte: PADILHA et al., 2006 


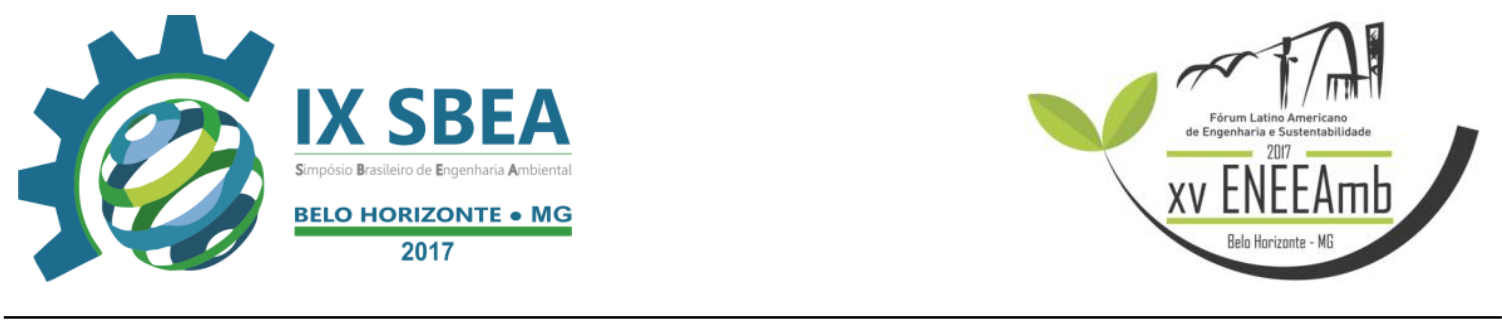

Desta forma foram quantificação o potencial energético global e por bairro em consequência dos resíduos. Simulação da geração de energia elétrica por ponto de venda identificado, levando em conta o volume de sacas de açaí produzidas.

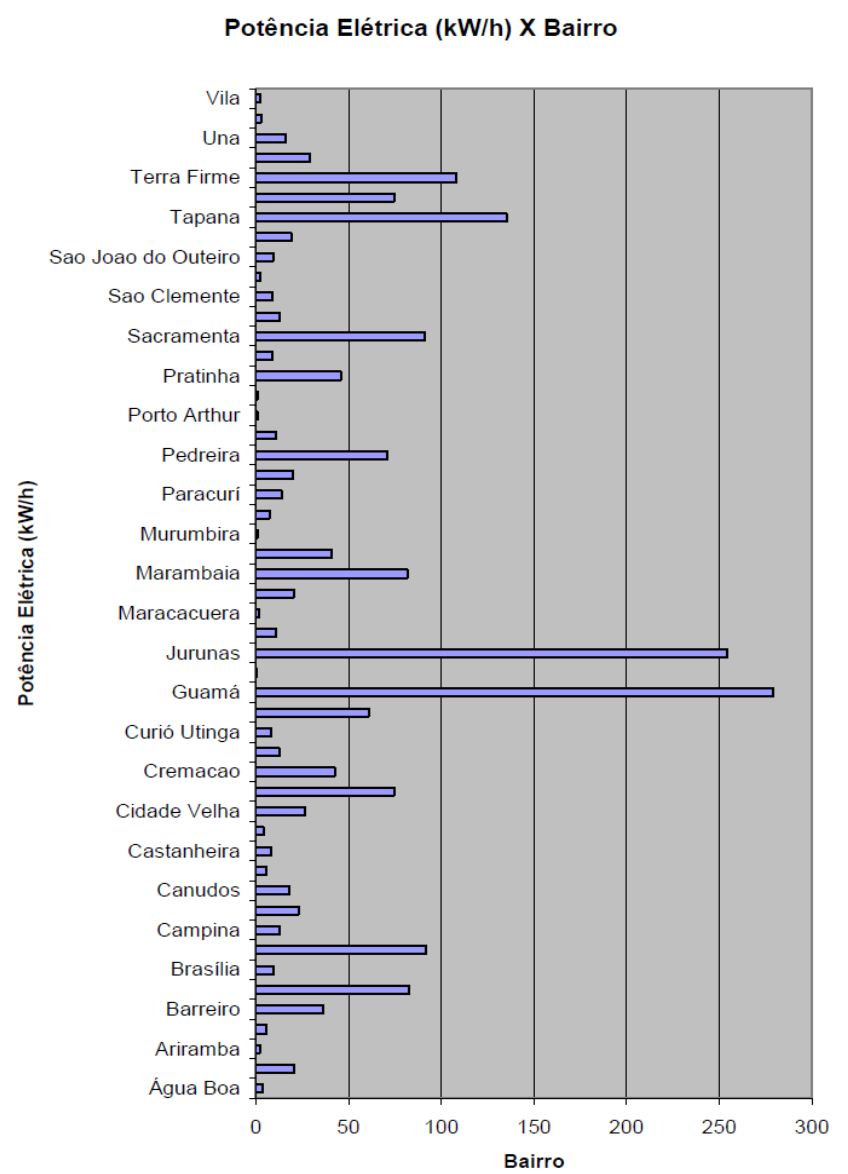

Gráfico 6. Potencial Elétrico de Geração $(\mathrm{kW})$ por bairro

Fonte: PADILHA et al., 2006

\section{CONCLUSÕES/RECOMENDAÇÕES}

Atualmente, na capital paraense, não há um trabalho voltado especificamente para coleta, transporte e destinação final dos resíduos e apesar do batedor ser o responsável pela destinação do resíduo, esse material geralmente é recolhido junto ao lixo domiciliar. Os caroços de açaí são despejados em lixões a céu aberto por carroceiros ou nos canais da capital, causando assoreamento e alagamentos, essa marca cultural gera um enorme problema ambiental, os sacos de caroços poluem calçadas e canais e ainda 


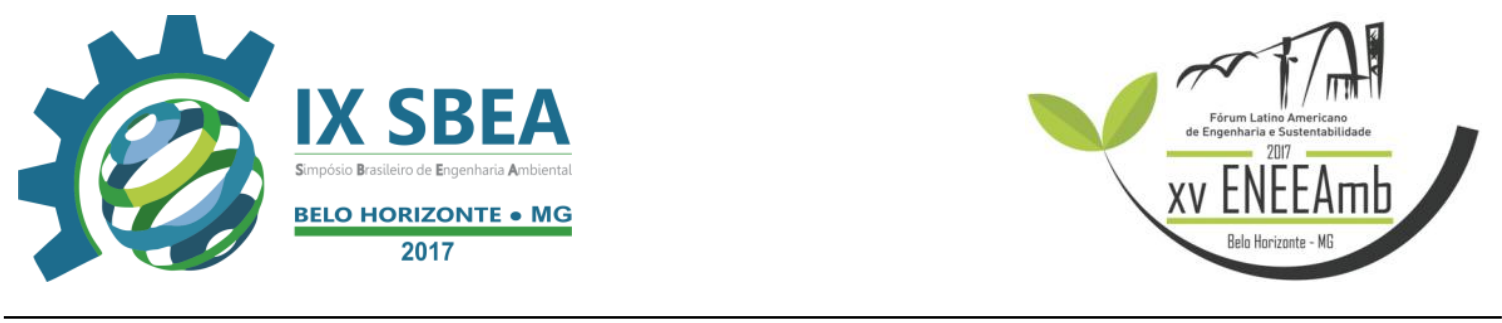

não há uma solução em funcionamento para sua destinação, apesar de haverem muitos estudos que certificam a possibilidade de uso comercial destes resíduos. Dos 20 batedores entrevistados no período da safra são gerados 24.288 rasas de açaí, e 17.014 rasas na entre safra.

Como fonte energética na Amazônia e particularmente no Estado do Pará, o caroço do açaí, apresenta-se com viabilidade de utilização, promovendo uma solução aos problemas de falta ou escassez de energia elétrica, inclusive nas atividades domésticas, de panificadores industriais e demais indústrias que utilizam lenha.

Conforme os dados levantados por Padilha et al (2006), ao todo 1.657 pontos de venda de açaí, gerando um volume de 5.707 sacas gerando aproximadamente 2 MW de potência para utilização de energia elétrica através de um ciclo Rankine. Os bairros do Jurunas e Guamá foram os que apresentaram o maior potencial seguido pelos bairros do Tapanã e da Terra Firme, isto se deve a alta concentração de pontos de vendas nestes bairros.

Bairro como Bengui e Cremação apesar de possuírem poucos pontos de venda de açaí, se sobressaem sob os demais, pelo fato de pequenos pontos possuírem alta produtividade, caracterizando empresas de açaí.

O registro em banco de dados permitirá a elaboração de outras simulações, dada a facilidade de manipulação das informações oferecidas por este tipo de ferramenta. Tornando uma importante referência para pesquisas futuras e gestão dos resíduos para a geração de energia, além de gerar emprego e renda, minimiza os impactos ambientais causados pela destinação inadequada dos resíduos advindos do caroço do açaí.

\section{REFERÊNCIAS BIBLIOGRÁFICAS}

ASSOCIAÇÃO BRASILEIRA DE NORMAS TÉCNICAS, São Paulo, NBR 10.004 Resíduos Sólidos; Classificação. São Paulo, 2004.

ASSOCIAÇÃO BRASILEIRA DE NORMAS TÉCNICAS. São Paulo. NBR 10007. Amostragem de resíduos. São Paulo. 2004

ANDRADE, L.C. Et al. Adoção de novos paradigmas na organização e gestão de empreendimentos solidários: um estudo sobre o processo produtivo do açaí através 
das associações e cooperativas no Território Rural do Baixo Tocantins - Pará Brasil. XLVI Congresso da Sociedade Brasileira de Economia, Administração e Sociologia Rural - SOBER. Acre, 2008.

ANDRADE, JBL. Análise do fluxo e das características físicas, químicas e microbiológicas dos resíduos de serviço de saúde: proposta de metodologia para o gerenciamento em unidades hospitalares. São Carlos -SP, 1997.

BRASIL. Ministério Da Agricultura e Do Abastecimento. Instrução Normativa $n^{\circ} 01$ de 07/01/2000. BRASIL. Manual de Saneamento. $3^{\text {a }}$ ed. Brasília: Ministério da Saúde: Fundação Nacional de Saúde, 1999.

BRASIL. Instituto Brasileiro de Geografia e Estatísticas. Produção da Extração Vegetal e da Silvicultura. Rio de Janeiro, v. 25, 2010.

CARNEIRO, P. F. N. Caracterização e avaliação da potencialidade econômica da coleta seletiva e reciclagem dos Resíduos Sólidos domiciliares gerados nos municípios de Belém e Ananindeua - Pa. Belém, 2006.

EMBRAPA Amazônia Oriental: Técnicas de Irrigação possibilitam a produção de açaí na entre safra. Disponível em: https://www.embrapa.br/busca-de-noticias//noticia/1913146/tecnicas-de-irrigacao-possibilitam-a-producao-de-acai-na-entressafra. Acesso em: 21 maio. 2017.

FERNANDES, D. A.; CARDODO, A. C. D.; ALMEIDA, L. M. L; KATO, E. S. O CIRCUITO INFERIOR DA ECONOMIA URBANA NA AMAZÔNIA: um estudo sobre o papel do mercado de batedores artesanais de açaí na economia da Região Metropolitana de Belém. Associação Brasileira de Estudos Regionais. 2015.

FURASTÉ, P. A. Normas Técnicas para o Trabalho Científico: Elaboração e Formatação. Explicitação das Normas da ABNT. - 14 ed. - Porto Alegre: s.n., 2007.

INSTITUTO DE PESQUISA TENOLÓGICA / COMPROMISSO EMPRESARIAL PARA A RECICLAGEM. Manual de Gerenciamento Integrado de Resíduos Sólidos. São Paulo: IPT/CEMPRE, 2000.

MACHADO, G. B. Disposição Final Ambientalmente Adequada de Rejeitos.2016.

PADILHA, J. L; CANTO, Sergio Aruana Elarrat; RENDEIRO, Gonçalo. Avaliação do potencial dos caroços de açaí para geração de energia. Universidade Federal do Pará. 2006.

SILVA, I. T.; ALMEIDA, Arthur da Costa; MONTEIRO José Humberto Araújo; SILVA, Isa Maria Oliveira; ROCHA, Brígida Ramati Pereira. Uso do caroço de açaí como possibilidade de desenvolvimento sustentável do meio rural, da agricultura familiar e de eletrificação rural do Estado do Pará. Universidade Federal do Pará. 